\title{
Aprendizagem baseada em projetos: organização e execução de uma proposta formativa na educação a distância
}

\author{
Luciano Gamez ${ }^{1}$ \\ Cícera A. Lima Malheiro²
}

\section{RESUMO}

Neste trabalho, apresentamos o relato de experiência de um processo de organização, execução e implementação de uma proposta formativa para o Ensino Superior a distância, que partiu da utilização da Aprendizagem Baseada em Projetos (ABP) como estratégia metodológica e pedagógica. A experiência deu-se no contexto da disciplina Projeto Integrado do curso superior de Tecnologia em Design Educacional da Universidade Federal de São Paulo. Essa disciplina teve como objetivo direcionar e promover a aplicação prática de conteúdos, de forma interdisciplinar, do conjunto de disciplinas de uma Unidade Curricular situada no contexto de trabalho do designer educacional na educação formal. A descrição dessa experiência é apresentada, bem como os resultados colhidos na avaliação, pelos alunos dessa proposta formativa, relatada como positiva e significativa, tanto pelos discentes como pelos demais professores do curso, por proporcionar a integração entre ações teóricas, reflexivas e práticas no desenvolvimento de competências profissionais específicas do designer educacional.

Palavras-chave: Aprendizagem Baseada em Projetos. Educação a distância. Design educacional.

\footnotetext{
1 luciano.gamez@unifesp.br - Universidade Federal de São Paulo

2 malheiro@unifesp.br - Universidade Federal de São Paulo
} 


\section{Project-based learning: organization and execution of a training proposal in distance education}

\section{ABSTRACT}

In this paper we present the experience report of an organizational process, execution and implementation of a training proposal for higher distance education, which started from the use of Project-Based Learning (PBL) as a methodological and pedagogical strategy. The experience took place in the context of the discipline "Integrative Project" of the course Technology in Instructional Design at the Federal University of São Paulo, which aimed to direct and promote the practical application of contents, in an interdisciplinary manner, from the set of disciplines situated in the context of the instructional designer's work in formal education. The description of this experience is presented, as well as the results collected in the evaluation of this training proposal, by the students, reported as positive and significant, both by the students and by the other professors of the course, for providing the integration between theoretical, reflective and practical actions in the development of specific instructional designer professional skills.

Keywords: Project-Based Learning. Distance Education. Instructional Design. 


\section{INTRODUÇÃO}

A Aprendizagem Baseada em Projetos (ABP) - Project Based Learning (PBL) - consiste em um modelo de ensino e aprendizagem que possibilita aos estudantes confrontarem-se com problemas do mundo real e proporem soluções para tentar resolvê-los. A concepção desse modelo tem sido defendida como um processo eficaz que resulta em alto nível de envolvimento e desempenho dos estudantes (BENDER, 2014), pois foca nas vivências práticas, levando a uma maior participação desses discentes durante as atividades propostas. De acordo com o referido autor, os processos orientados por meio dessa abordagem contribuem para uma gestão acadêmica centrada em colaborar com os processos de ensino e aprendizagem dos alunos, levando-os a desenvolver competências e habilidades úteis e necessárias requeridas no mundo real.

Outros termos também são empregados para designar as ações da ABP, tais como: aprendizagem baseada em problemas; aprendizagem investigativa; aprendizagem autêntica e aprendizagem por descoberta (BENDER, 2014). Embora se trate de terminologias diferentes, o autor esclarece que em todas elas as bases permanecem as mesmas, ou seja, os estudantes identificam e buscam resolver problemas do mundo real e, durante esse processo, desenvolvem diversos artefatos que podem ser usados para demonstrar seus conhecimentos e comunicar sobre suas formas de tomada de decisão. Segundo Costa (2020), não é necessário que o projeto seja grande, caro e complexo para ser um modelo de ABP, mas sim que seja relevante e que gere aprendizado significativo aos estudantes, envolvendo-os nas decisões, nas tarefas e na organização.

$\mathrm{Na} A B P$, são propostos processos de ensino-aprendizagem, nos quais envolvem ações teóricas, reflexivas e práticas, que ajudam a desenvolver competências específicas dos contextos profissionais. No caso deste trabalho, o contexto de atuação do designer educacional exige, cada vez mais, competências para: trabalho em equipe, boa relação interpessoal, bom uso da pesquisa, excelente comunicação, curiosidade, criatividade, proatividade, autonomia, uso assertivo dos recursos de tecnologias digitais no contexto educacional, manipulação de dados que orientem os processos de tomada de decisão, entre outras competências.

O objetivo deste texto é apresentar o processo de organização, execução e os resultados de uma proposta formativa desenvolvida no âmbito do curso superior de Tecnologia em Design Educacional (TEDE) da Universidade Federal de São Paulo, que utilizou a ABP como estratégia pedagógica.

A descrição dessa experiência é relatada, assim como o conteúdo - resultante da avaliação da proposta formativa realizada pelos estudantes do TEDE -, o qual foi incorporado e problematizado, sob a metodologia da APB, ao detalhamento do processo empregue na organização e execução dessa ação. 
O curso superior de Tecnologia em Design Educacional (TEDE) é organizado em cinco Unidades Curriculares (UC): Design educacional em contextos abertos e em rede; Design educacional em contextos não formais, culturais e inclusivos; Design educacional em contextos acadêmicos; Design educacional em contextos corporativos; Projeto em Design Educacional. Em cada uma das unidades curriculares, os estudantes desenvolvem projetos que integram as disciplinas propostas em cada UC.

Tendo como referência a abordagem da ABP, a disciplina Projeto Integrador 3 (PI3), que faz parte da Unidade Curricular Design Educacional em Contextos Acadêmicos, foi desenvolvida com uma carga horária de 120 horas, a partir da ementa: "construção de um curso, módulo ou disciplina acadêmica seguindo todas as etapas de conceituação e planejamento didáticopedagógicos geral - macro - e os documentos descritivos - micro - como roteiros e storyboards abordando as temáticas transversais" (UAB/UNIFESP, 2016).

O objetivo da disciplina PI3 foi direcionar e promover a aplicação dos conteúdos das demais disciplinas ministradas na mesma Unidade Curricular do TEDE e dos projetos de extensão universitária propostos, bem como trabalhar a prática profissional aplicada do designer educacional no contexto da educação formal. Como objetivos específicos, foram previstos: propiciar a vivência do trabalho em equipe multidisciplinar para o desenvolvimento de um projeto de design educacional, contemplando as etapas de planejamento, desenvolvimento, implementação e avaliação; apresentar as etapas de desenvolvimento de uma disciplina ou projeto de extensão no modelo de educação on-line ou híbrido; e promover a prática do Design Educacional no contexto formal de educação.

A proposta pedagógica adotada nessa disciplina foi delineada a partir das demandas apresentadas por profissionais da Educação Básica e do Ensino Superior, os quais apresentaram necessidades reais vivenciadas durante a pandemia da Covid-19. Tais demandas, oriundas de escolas públicas e de universidades, foram identificadas pelos alunos do TEDE em contato com seus demandantes.

\section{Quadro 1: Destaque de algumas das competências vinculadas às disciplinas}

\begin{tabular}{|l|l|}
\hline \multicolumn{1}{|c|}{ Competências a serem desenvolvidas } & \multicolumn{1}{c|}{ Disciplinas da UC3 } \\
\hline $\begin{array}{l}\text { Mapear e analisar competências e objetivos } \\
\text { educacionais esperados para o aluno egresso }\end{array}$ & Ensino e aprendizagem em contextos formais \\
\hline $\begin{array}{l}\text { Reconhecer as características dos espaços } \\
\text { educacionais. }\end{array}$ & Currículo, cultura escolar e acadêmica \\
\hline $\begin{array}{l}\text { Investigar e reconhecer as potencialidades das } \\
\text { tecnologias existentes e emergentes nos espaços } \\
\text { educacionais. }\end{array}$ & Tecnologias para a gestão acadêmica \\
\hline $\begin{array}{l}\text { Avaliar, selecionar, propor alterações e } \\
\text { aprimoramentos em materiais e recursos } \\
\text { educacionais. }\end{array}$ & $\begin{array}{l}\text { Design universal e linguagens para materiais } \\
\text { didáticos }\end{array}$ \\
\hline $\begin{array}{l}\text { Desenvolver uma proposta de gestão de produção } \\
\text { de cursos e materiais didáticos. }\end{array}$ & $\begin{array}{l}\text { A gestão de projetos em estruturas } \\
\text { organizacionais formais do ensino }\end{array}$ \\
\hline
\end{tabular}

Fonte: adaptado do manual do estudante na disciplina PI3. 
A utilização da metodologia da ABP, nesse cenário, integrou diferentes conhecimentos e buscou estimular o desenvolvimento de competências diversas - veja Quadro 1 - e necessárias no contexto de trabalho do DE na área acadêmica.

Considera-se importante destacar que cada disciplina, apesar de ter seus próprios objetivos de aprendizagem, contribuiu para o desenvolvimento de competências específicas vinculadas ao trabalho com projetos. Sendo assim, deram subsídios ao desenvolvimento do Projeto Integrador articulando as competências educacionais requeridas no semestre. A seguir, são destacados excertos da autoavaliação reflexiva realizada pelos estudantes sobre essa experiência.

(...) o projeto integrador estimula o uso de todas as disciplinas de acordo com o contexto do projeto. Nessa proposta, o encaixe das disciplinas aconteceu naturalmente, o que tornou o trabalho prático e dinâmico. [estudante B]

As atividades desenvolvidas para as disciplinas forneceram subsídios fundamentais para a análise, elaboração e implementação da proposta. [estudante C]

As ferramentas de gestão poderiam ter sido mais bem utilizadas por nós; por outro lado, os conhecimentos recebidos nas disciplinas de Design e de Pesquisa e Inovação ajudaram a materializar o projeto e a olhar de forma mais crítica para o produto que estávamos elaborando. [estudante $\mathrm{D}$ ]

Houve articulação clara entre as disciplinas, explicitada nas atividades e relatórios entregues. [estudante L]

Desde o início do semestre busquei me organizar para realizar as tarefas da disciplina e articulá-las à proposta do PI. Em alguns momentos, no entanto, tive dificuldade em dar conta das demandas propostas por elas junto às do $\mathrm{PI}$, tanto por conta da quantidade de atividades propostas quanto pela densidade das discussões propostas. [estudante $\mathrm{H}$ ]

Dentro da proposta do PI consegui aplicar diversas habilidades e conceitos estudados nas disciplinas e praticados na minha vida profissional. [estudante M]

Nesta UC3 todas as disciplinas caminharam com o Projeto Integrador, isso fez me sentir e desenvolver a minha educação formativa como um estudante a ao mesmo tempo na prática de um profissional DE. Pude acompanhar, articular e projetar o projeto educacional, compartilhar e receber informações inerente ao desenvolvimento do projeto. [estudante J]

Sem dúvida alguma vivenciamos de forma mais clara, neste semestre, como cada disciplina possui carga e potencial para sustentar decisões de alunos ao escolherem soluções para os protótipos desenvolvidos. Podemos atribuir que tal vivência é resultado direto do processo de planejamento elaborado para a UC3. [estudante P] 


\subsection{Ambiente virtual de aprendizagem}

O ambiente virtual de aprendizagem (AVA) utilizado para a organização da disciplina foi construído na Plataforma Moodle. $O$ desenho de interação foi implementado em formato de ícones de forma a organizar sequencialmente todas as ações pedagógicas previstas e facilitar o acesso e a navegação tanto em computadores (Figura 1), como em dispositivos móveis (Figura 2).

Figura 1: Interface acessada pelo computador

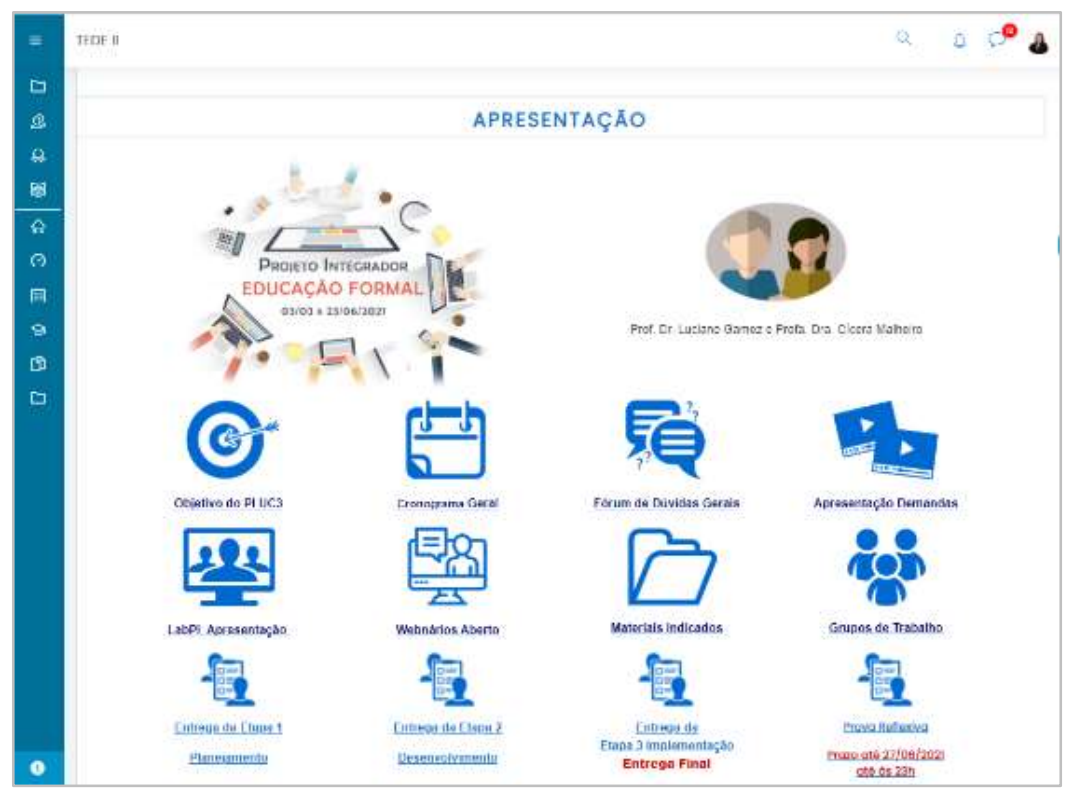

Fonte: captura de tela do AVA (2021).

Figura 2: Interface acessada pelo smartphone

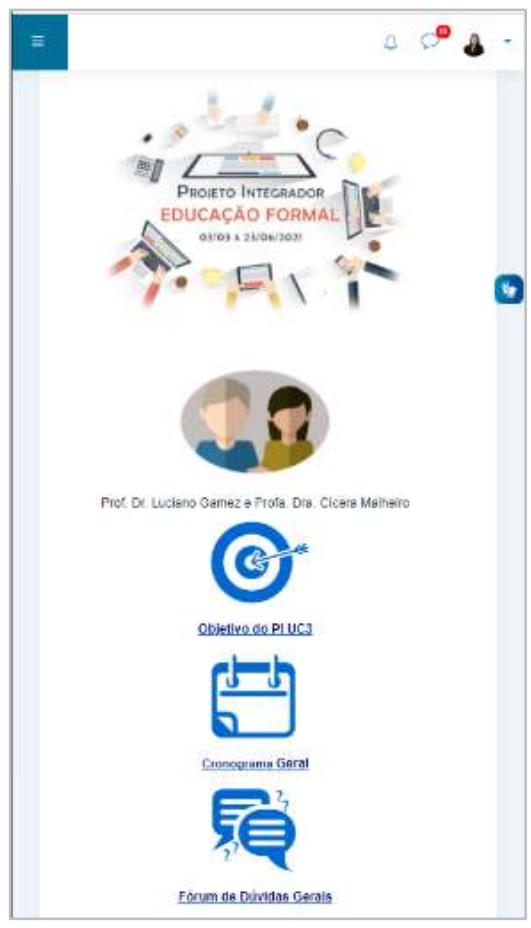

Fonte: captura de tela do AVA 
Quando questionamos se os estudantes encontraram com facilidade as orientações, informações e recursos para a condução do projeto no ambiente - considerando uma escala de 1 a 5, sendo 1 relacionado a pouca facilidade e 5 a muita facilidade - constatou-se que os posicionamentos foram distribuídos entre as escalas 2 a 5 , embora a maioria indicou que encontrou com muita facilidade as orientações, informações e recursos.

Ainda sobre o ambiente, questionamos o quão agradável era a interface e o quanto era fácil a navegação nela. Considerando uma escala de 1 a 5 , sendo 1 muito pouco agradável e 5 muito agradável, e sobre a navegabilidade, sendo $1 \mathrm{com}$ pouca facilidade e 5 muita facilidade, notou-se que em relação ao aspecto agradável as escalas de pontuação foram 4 e 5, ou seja, muito agradável. Em relação à navegação, foram distribuídas entre as escalas 2 a 5. Mesmo assim, a maioria avaliou que houve muita facilidade na navegação no ambiente. No geral, considerou-se que o ambiente foi adequado para a maioria dos estudantes, pois as escalas com maior pontuação foram as 4 e 5 .

\section{Gráfico 1: Avaliação da Interface do ambiente}

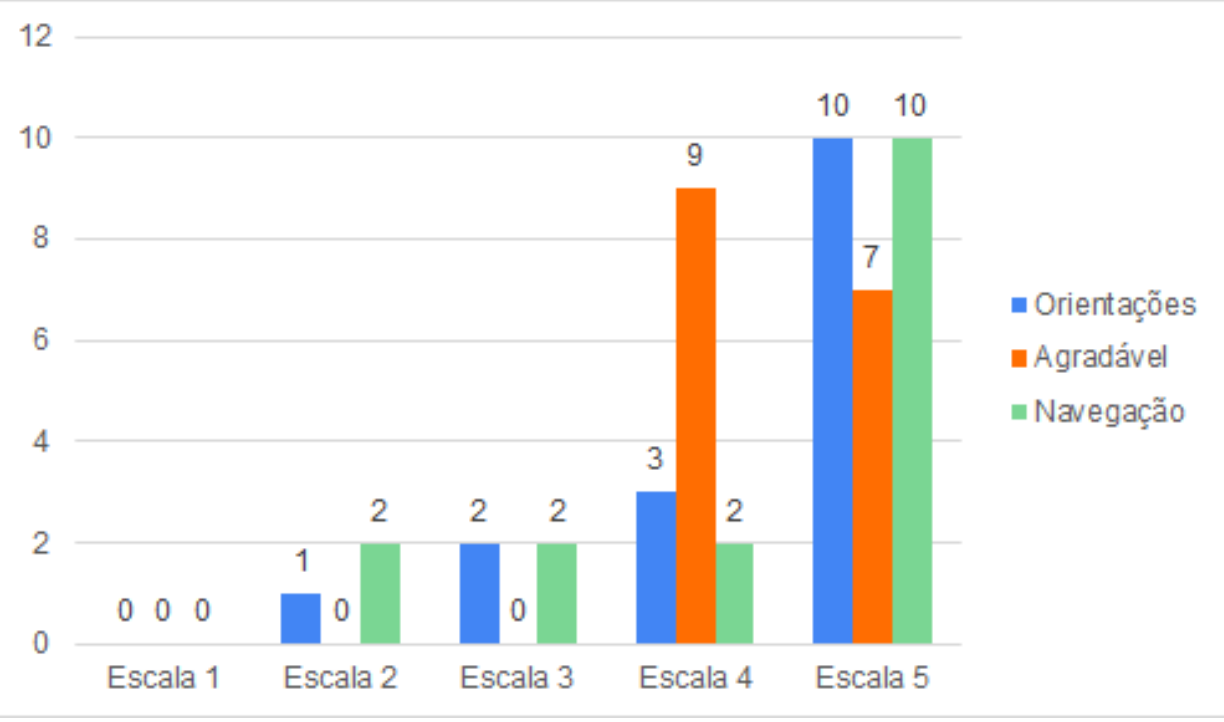

Fonte: elaborado pelos autores

Tendo como referência a abordagem ABP, o tempo de "trabalho" dos estudantes foi estrategicamente organizado em um semestre, dividido em três etapas e articulado junto ao período de oferta das disciplinas no semestre. Durante esse período, os estudantes dedicaram sua atenção a seus projetos enquanto buscavam soluções para as demandas apresentadas.

$\mathrm{Na}$ abordagem $\mathrm{ABP}$, os discentes precisam planejar o trabalho de modo cooperativo com a sua equipe, à medida que avançam na solução do problema, desenvolvendo um plano de ação e começando a elaborar uma descrição ou diretriz para o desenvolvimento de seus produtos ou artefatos (LARMER; MERGENDOLLER, 2010 apud BENDER, 2014).

Para que os estudantes, além de construir conhecimentos individuais, pudessem desenvolver competências de trabalho em equipe e ações colaborativas na gestão e desenvolvimento de projetos, foi proposta a criação de pequenos grupos. 


\section{EmRede}

Embora foi disponibilizado no AVA um espaço de comunicação para cada grupo (Figura 3), os estudantes escolheram outros meios e ferramentas para agilizar a comunicação, tais como o WhatsApp.

Figura 3: Tela da ferramenta Fórum organizada em grupos

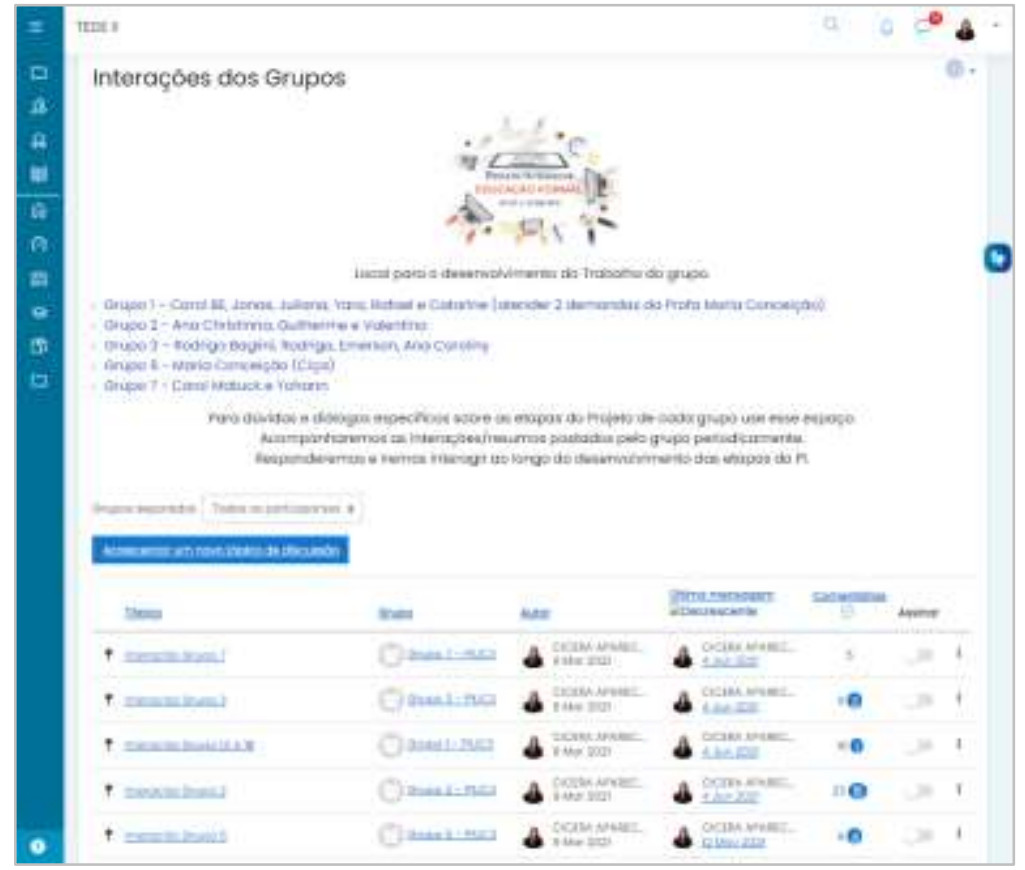

Fonte: captura de tela do AVA (2021).

Sobre o processo de comunicação com os grupos, a partir das ferramentas disponibilizadas - fórum do Moodle e WhatsApp -, procuramos entender se a utilização dos fóruns dentro do ambiente foi prática para esclarecer dúvidas com os colegas e com os professores, conforme apresentado no Gráfico 2.

\section{Gráfico 2: Avaliação da Comunicação via Fórum e WhatsApp}

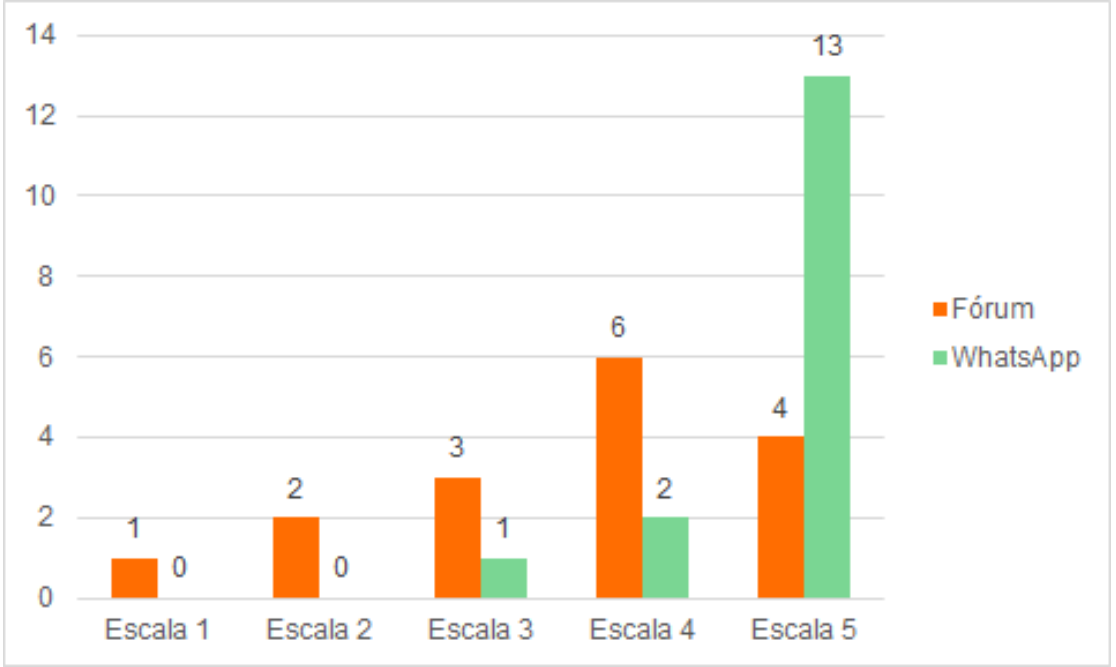

Fonte: elaborado pelos autores (2021). 
Considerando uma escala de 1 a 5, sendo 1 pouco prático e 5 muito prático, percebemos que as opiniões foram distribuídas entre as escalas, sendo a 4 e a 5 a mais pontuada. Da mesma forma, quando questionamos se a utilização da ferramenta WhatsApp facilitou a comunicação com o grupo e com os professores e demandantes, ao considerar uma escala de 1 a 5 , sendo 1 indicativo de que facilitou pouco e 5 de que facilitou muito, notamos que, embora alguns tenham pontuados as escalas 3 e 4, consideramos que a comunicação via WhatsApp foi mais facilitada na opinião da maioria.

Bender (2014) esclarece que devido à abordagem ABP se assemelhar com problemas enfrentados na vida, a estrutura para se chegar à solução pretendida deve ser criada. Dessa maneira, por meio desse processo, os estudantes precisam trabalhar em equipe de forma cooperativa, articulando as informações para apresentar uma solução eficaz a fim de resolver o problema. $O$ autor destaca que cada membro da equipe pode usar os seus pontos fortes para cumprir a meta do grupo ao mesmo tempo que aprende com os demais. Os relatos a seguir ilustram a percepção dos estudantes quanto ao trabalho realizado em grupo.

De acordo com as minhas atribuições no desenvolvimento do projeto, como contribuições nas etapas de criação, pesquisa, gestão de prazos e documentação do projeto, consegui atender e colaborar com os meus colegas. [estudante A]

Outro ponto relevante foi a divisão de responsabilidades entre os membros do grupo e a autonomia para tomada de decisões sempre que necessário. Como grupo, todos assumimos a responsabilidade na entrega de um produto, cada qual com sua parcela de responsabilidade. (...) estive à frente da organização de todas as atividades entregues, e busquei junto ao grupo soluções e divisões de tarefas que se adequassem a todos. [estudante $\mathrm{H}$ ]

O grupo interagiu conforme a demanda e havia muita troca entre nós, seja nas entregas individuais ou do PI. No grupo, cada um tinha sua demanda e, ao final, construía o todo. [estudante B]

Acredito que tive uma boa performance durante o $\mathrm{PI} 3$, visto que sempre estive presente em todas as etapas de desenvolvimento e contribuí, de fato, em todas as produções realizadas pelo grupo. Não houve qualquer problema para trabalhar com o grupo. [estudante L]

O processo de compor um grupo de trabalho de forma totalmente remota se mostrou bastante desafiador e em muitos momentos enfrentei dificuldades para me expressar, devido a pouca intimidade com os colegas (ou no mínimo, uma intimidade "mediada") e em alguns momento senti falta de encontros presenciais para resolver certas questões que parecem só fazer sentido quando se está presente; no entanto; com o tempo todas as questões foram se resolvendo, principalmente devido à vontade dos colegas em concluir os trabalhos. Aqui também houve um aprendizado muito grande, na forma de se relacionar e trabalhar virtualmente. [estudante $\mathrm{M}$ ]

Me senti acolhido com o grupo. Cada integrante pôde, a partir de suas habilidades mostrar o melhor. [estudante N] 
Os prazos sempre foram cumpridos e as responsabilidades sempre foram bem partilhadas. Achei interessante que grande parte do trabalho foi feito de maneira síncrona entre os integrantes do grupo: percebemos que o trabalho ganhava em qualidade quando todos eram ouvidos nas tomadas de decisão. Acabei ficando bem satisfeito com o produto final e gostei de participar do Congresso Unifesp como uma continuação desse projeto. Para mim foi o PI de mais aprendizagem, mesmo sendo o contexto acadêmico aquele no qual eu possuo maior familiaridade. [estudante 0 ]

Quando os estudantes foram questionados se participar do grupo ajudou no desenvolvimento do projeto, em uma escala de 1 a 5 , sendo 1 ajudou pouco e 5 ajudou muito, observou-se também uma porcentagem elevada nas escalas distribuídas entre 4 e 5 , demonstrando que $100 \%$ dos discentes afirmaram que o grupo ajudou muito no desenvolvimento do projeto (Gráfico 3).

\section{Gráfico 3: Avaliação se o grupo ajudou no projeto}

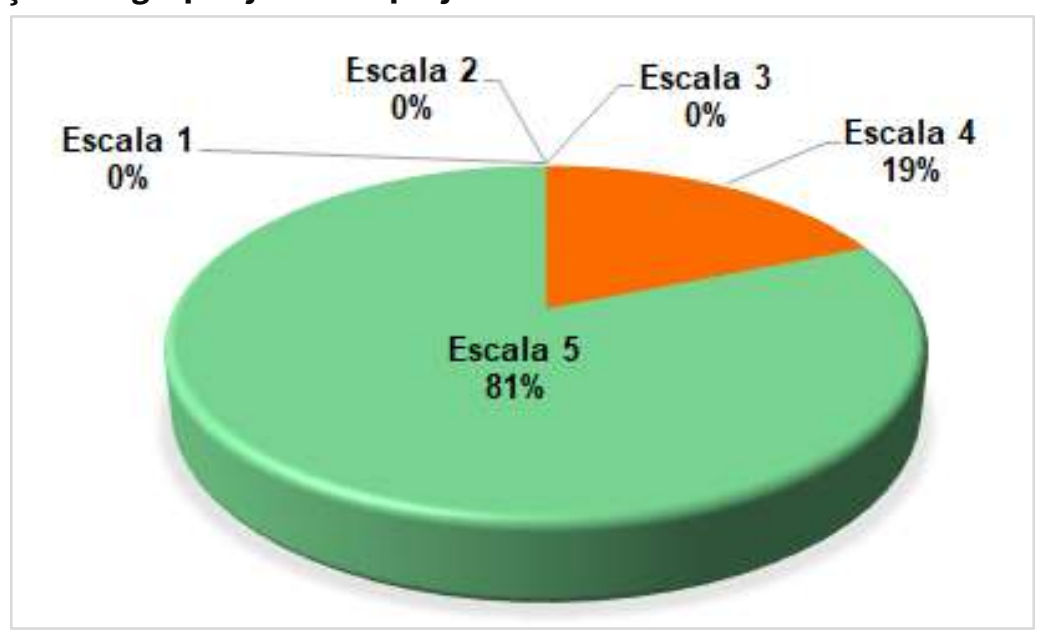

Fonte: elaborado pelos autores (2021).

O trabalho em equipe na abordagem da ABP é considerado essencial, uma vez que, no decorrer do processo de desenvolvimento das etapas do projeto, os estudantes realizam uma escuta e organizam um brainstorming para entender o problema, elencar hipóteses e pensar em possíveis soluções. No decorrer do processo, precisam dividir responsabilidades, tomar decisões cooperativamente sobre como prosseguir e quais caminhos trilhar.

Além disso, ocorre o refinamento das ideias, estas são apoiadas em pesquisas e mapeamento de recursos. Os alunos fazem experimentações e geram novos questionamentos. Durante o processo, ou ao final, desenvolvem um produto ou múltiplos produtos concretos materiais didáticos, implementação de ambiente digital, relatórios entre outros. Nesses artefatos produzidos, os conceitos aprendidos são materializados. 
Diferente de outros processos metodológicos em que ocorre a transmissão de conteúdo de forma vertical do professor para os estudantes, na abordagem ABP, o papel dos professorescoordenadores do Projeto foi de atuar como mediadores dos processos de ensino e aprendizagem, comunicando-se com cada grupo, orientando e apoiando de forma horizontal as ações frente ao desenvolvimento de cada etapa prevista na condução do projeto, buscando interferir somente o necessário, mais especificamente, indicando fontes de pesquisas, recursos para enriquecer o repertório de conhecimentos dos estudantes.

Quando a demanda não estava sendo muito bem compreendida entre os alunos, foi preciso ajudar esclarecendo ou orientando-os nas rotas que precisavam ser seguidas e no foco que deveriam tomar, para evitar, assim, rumos inadequados que poderiam não levar a resultados satisfatórios.

Além da ferramenta fórum disponibilizada no AVA - figura 4 -, foram organizados grupos no WhatsApp para agilizar a comunicação.

\section{Figura 4: Tela do Fórum Geral}

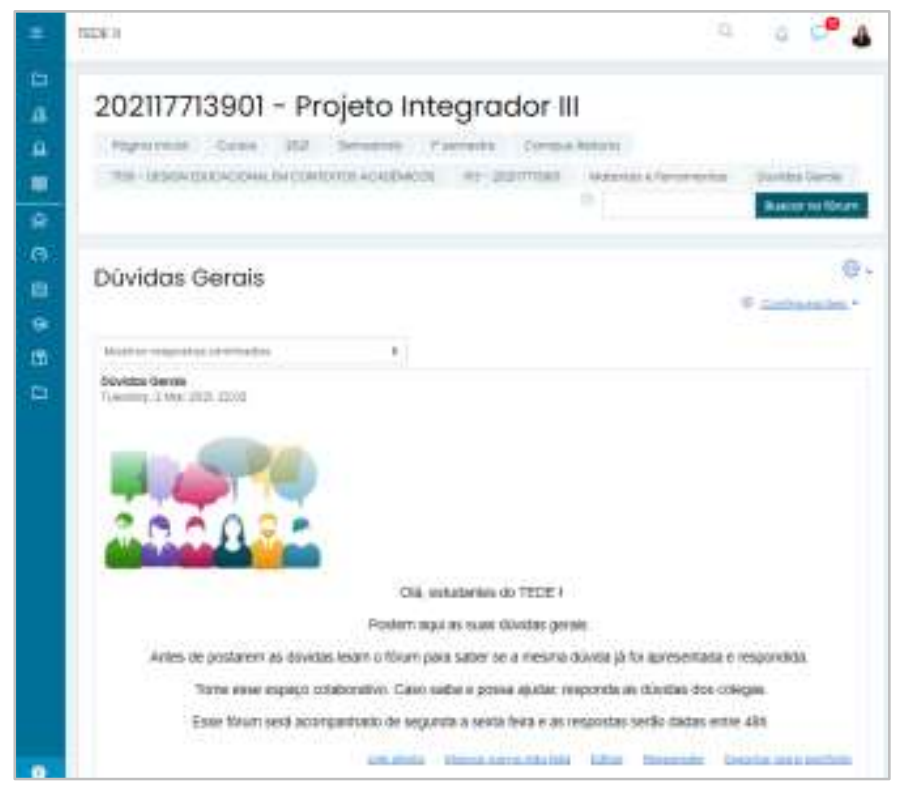

Fonte: captura de tela do AVA (2021).

Diante do papel dos professores-coordenadores do projeto no esclarecimento das dúvidas e orientações, buscou-se compreender o quanto essa ajuda foi percebida pelos estudantes. Assim, em uma escala de 1 a 5 , sendo 1 considera que os professores ajudaram pouco e 5 que ajudaram muito, percebe-se que $81 \%$ dos estudantes afirmaram que os professores ajudaram muito. 
Gráfico 4: Orientações e esclarecimento de dúvidas

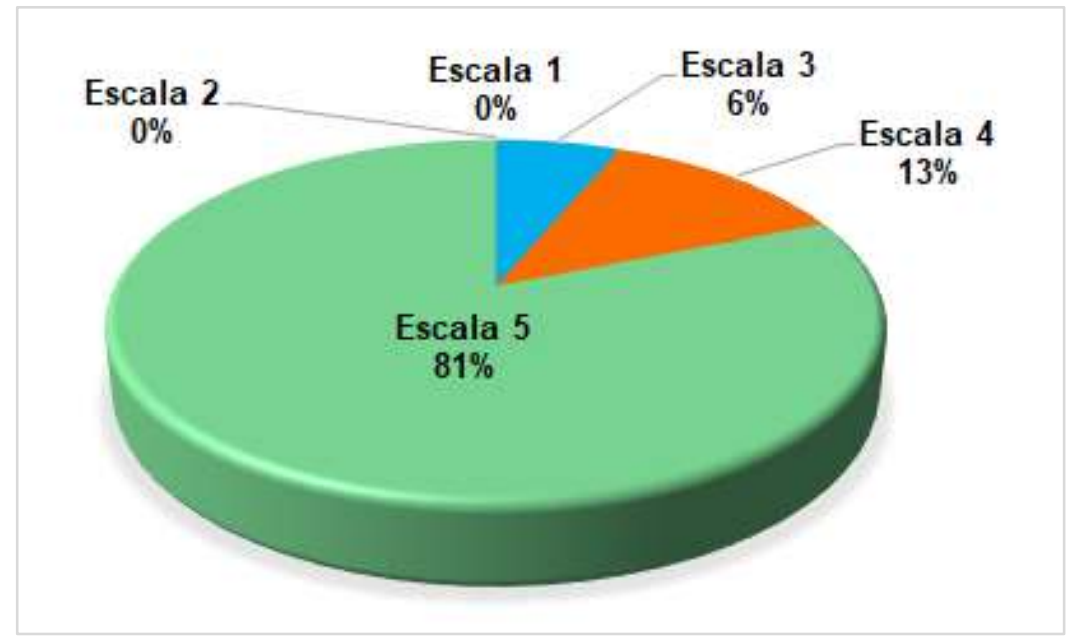

Fonte: elaborado pelos autores (2021).

Os excertos destacados a seguir ilustram a percepção de alguns estudantes diante do trabalho realizado pelos professores-coordenadores do PI.

A troca com os professores fluiu sem ruídos, pois o acesso estava facilitado. [estudante B]

O apoio e pronto atendimento dos professores para sanar dúvidas, realizando reuniões com o grupo, bem como o uso do WhatsApp para questões pontuais, foi um grande acerto e nos auxiliou demais no processo comunicativo. [estudante C]

(...) foram primordiais a compreensão dos professores e o apoio de meus colegas que se dispunham a ajudar, a discutir e a promover reflexões sobre a profissão de Designer Educacional em seus diferentes aspectos. [estudante $\mathrm{C}$ ]

(...) neste semestre me desenvolvi melhor em relação aos semestres passados em relação as disciplinas e atividades realizadas conforme o feedback feito pelos professores(as), e em especial com a disciplina de P.I. que trabalha de forma integrada com todas as demais. [estudante D]

O papel dos professores-coordenadores consistiu também em intermediar, quando necessário, e acompanhar a comunicação entre os alunos e os professores-colaboradores, sugerindo aprimoramentos entre as etapas dos projetos por meio de orientações e feedbacks constantes. Nesse processo, os estudantes passaram de meros receptores passivos a agentes ativos no seu processo de aprendizado.

\section{4}

DISCIPLINAS DA UNIDADE CURRICULAR E AS AÇÕES ARTICULADAS NA ABP

Compreendemos que incorporar a metodologia da ABP em contextos formativos não é tarefa fácil; exige uma mudança de planejamento e trabalho dos professores envolvidos, e isso requer uma mudança de mentalidade para que seja desenvolvido um trabalho interdisciplinar. 
Fazenda (2002, p. 11) define que "a interdisciplinaridade é uma nova atitude diante da questão do conhecimento, de abertura à compreensão de aspectos ocultos do ato de aprender e dos aparentemente expressos, colocando-os em questão". Nesse contexto, a autora reforça que a interdisciplinaridade se pauta numa ação em movimento, o que exige, portanto, na prática, uma profunda imersão no trabalho cotidiano, pautado em cinco princípios que subsidiam uma prática docente interdisciplinar: humildade, coerência, espera, respeito e desapego.

Yared (2008, p. 165), ao refletir sobre esse conceito, aponta que:

[...] a interdisciplinaridade é o movimento (inter) entre as disciplinas, sem a qual a disciplinaridade se torna vazia; é um ato de reciprocidade e troca, integração e voo; movimento que acontece entre o espaço e a matéria, a realidade e o sonho, o real e o ideal, a conquista e o fracasso, a verdade e o erro, na busca da totalidade que transcende a pessoa humana. Creio que a interdisciplinaridade leva o aluno a ser protagonista da própria história, personalizando-o e humanizando-o, numa relação de interdependência com a sociedade, dandoIhe, sobretudo, a capacidade crítica no confronto da cultura dominante e por que não dizer opressora, por meio de escolhas precisas e responsáveis para a sua libertação e para a transformação da realidade.

Vale destacar que esse trabalho interdisciplinar, ancorado no método da ABP, é adotado no currículo do curso superior de Tecnologia em Design Educacional e, logo, os docentes que ministram as disciplinas do curso são desafiados constantemente a trabalhar em parceria a partir da lógica da ABP. Sem perder as características de suas próprias disciplinas, os professores propõem atividades que apoiam o desenvolvimento dos projetos que estão sendo desenvolvidos pelos estudantes.

Esse alinhamento é feito por meio de reuniões de alinhamento, nas quais os professores que coordenam os projetos apresentam sua proposta de Projeto Integrador, e os professores das disciplinas esclarecem suas dúvidas, fazem sugestões e juntos todos definem as atividades que serão solicitadas no projeto final dos alunos e que serão articuladas e avaliadas nas disciplinas da Unidade Curricular. Essa organização é fundamental, uma vez que a ABP exige uma atitude interdisciplinar entre os docentes.

Mesmo com essas definições e articulações realizadas no planejamento pedagógico entre os professores e coordenadores dos projetos, durante o desenvolvimento desses projetos, alguns estudantes podem apresentar dúvidas, por isso a comunicação entre os docentes deve ser estabelecida para realizar possíveis ajustes no percurso, ou seja, adequações no planejamento visando aprimorar os processos e os esclarecimentos necessários.

Ao longo do desenvolvimento da disciplina PI3, foi necessário estimular a imaginação dos estudantes, incentivando-os a irem atrás de soluções, envolvendo-os na exploração do contexto de cada projeto, no desenvolvimento de ideias a partir do conhecimento adquirido nas atividades propostas nas disciplinas da Unidade Curricular e na comunicação estabelecida pelas equipes dos projetos.

Rule e Barrera (2008 apud BENDER, 2014, p. 25) explicam que a integração de disciplinas variadas com as diversas habilidades de pensamento na ABP ajuda os professores a trabalharem por meio de padrões de conteúdos vastos, ensinando os estudantes a enxergarem a conectividade das grandes ideias dentro das várias áreas do currículo. 
Vale esclarecer que a transdisciplinaridade esteve presente no desenvolvimento dos projetos, em que os conteúdos requeridos ultrapassaram o que foi previsto na grade curricular. Sendo assim, foi preciso, em alguns grupos, contar com professores-mentores que se dispuseram a colaborar trazendo outros conteúdos e atividades para compartilhar com os estudantes em encontros paralelos às demais atividades planejadas, tais como explicações práticas para configurar a plataforma Moodle e esclarecimentos sobre como implementar objetos utilizando o recurso de realidade aumentada.

\subsection{Etapas previstas para a organização das atividades}

Embora algumas propostas da ABP sejam desenvolvidas a partir de cenários fictícios ou no atendimento de um problema geral que cada grupo se debruce para resolver uma parte específica, optamos por apresentar demandas reais e distintas para cada grupo escolher e desenvolver um projeto autêntico.

Dessa forma, na metodologia empregada na disciplina PI3, a abordagem da ABP foi organizada por meio de um processo contínuo de atividades, cujo propósito foi atender a desafios de demandas reais de Educação decorrentes da pandemia de Covid-19. Assim, além da cientificidade incorporada em todo o processo de cada projeto desenvolvido pelos estudantes, 0 resultado previsto para cada um deles buscou contribuir com um problema educacional, pensado para públicos reais. Alguns excertos da autoavaliação reflexiva dos estudantes são destacados, a seguir, e ilustram a visão dos estudantes sobre a importância que atribuíram ao fato de trabalharem com contextos reais, incluindo suas motivações, interesses e envolvimentos nas ações implementadas nos projetos

O processo do Projeto Integrador 3 possibilitou lidar com demandas reais do contexto acadêmico. Estabelecer parceria com o departamento da universidade foi enriquecedor para exercitar algumas ferramentas aprendidas em semestres anteriores, como: a escuta ativa e o codesign. Tinha interesse particular por essa demanda do (...), pois abordava algo muito próximo à minha profissão (...). Assim, procurei conhecer o contexto da demanda (...). [estudante C]

Consegui perceber um grande envolvimento da minha parte em relação ao desenvolvimento do PI. Desde a apresentação das propostas, já me interessei (...). A partir dessa motivação inicial, consegui articular-me de maneira a exercer alguma liderança em meu grupo de $\mathrm{Pl}$, utilizamos dos conhecimentos trazidos nas disciplinas para pensarmos e desenharmos o curso. [estudante 0 ]

De acordo com Bender (2014), o foco nas experiências de aprendizagem autênticas vinculadas à resolução de tarefas em um mundo real, é uma característica presente em praticamente todas as experiências de ABP. O autor esclarece que, em geral, aumenta a motivação dos estudantes para participar ativamente dos projetos.

Para um melhor alinhamento entre as disciplinas que compõem a Unidade Curricular III e com vista ao desenvolvimento do PI3, foram organizadas e previstas três etapas para a condução do projeto: planejamento, desenvolvimento e implementação, que são descritas a seguir. 


\subsubsection{Etapa de planejamento}

Primeiro foram apresentadas algumas demandas de problemas reais vivenciados no cotidiano da educação formal, em um contexto pandêmico, por professores externos que concordaram em estabelecer parcerias conosco para o desenvolvimento da proposta desenhada para a disciplina Projeto Integrador 3.

De acordo com Bender (2014), como aspecto introdutório, deve ser fornecido aos estudantes uma "âncora". Nesse caso, foram utilizadas narrativas apresentadas em vídeos por cada demandante parceiro. Por meio dessas narrativas, foram apresentadas as demandas e esclarecida a importância e a razão pelas quais essas demandas deveriam ser solucionadas. 0 autor destaca que na abordagem ABP a âncora é de extrema importância, pois deve proporcionar um bom motivo para que os estudantes queiram realizar um projeto ou solucionar um problema em particular.

Nesse caso, a âncora - em formato de vídeo - apresentava um problema vivenciado no contexto formal da educação por professores do Ensino Superior e da Educação Básica, estes que durante a execução do projeto atuaram como professores-colaboradores e demandantes.

Inicialmente os estudantes estabeleceram um processo de diálogo com os professorescolaboradores, a fim de entenderem as demandas e os respectivos contextos em que cada projeto seria desenvolvido. Esse processo foi efetuado tendo como referência uma escuta e uma análise contextual.

A partir desse primeiro contato entre o grupo e os professores-colaboradores, foram definidas a questão motriz, e, com um foco, o projeto foi estruturado por cada grupo, que se envolveu em uma série complexa de tarefas para planejar e organizar as atividades que deveriam ser desenvolvidas, com o objetivo de encaminhar possíveis soluções para os problemas apresentados. Para Bender (2014), a questão motriz serve tanto para motivar os discentes quanto para ajudá-los a delinear parâmetros específicos que orientem o trabalho. $O$ autor destaca ainda que:

A questão motriz é o foco principal da experiência de ABP. Ela pode ser desenvolvida com antecedência pelo professor ou, se o tempo permitir, pode se usar as equipes de estudantes para desenvolver essa questão como uma parte do próprio projeto (BARELL, 2007; LARMER; MERGENDOLLER, 2010 apud BENDER, 2014).

Em conjunto com a âncora, a questão motriz deve tanto despertar a atenção dos estudantes quanto a focar seus esforços nas informações específicas de que eles precisam para abordar o problema (BENDER, 2014, p. 44).

Conforme destaca Bender (2014), os estudantes devem perceber o projeto como sendo pessoalmente significativo para eles, para alcançarem o máximo de envolvimento na resolução do problema. Por isso, enquanto grupo, os estudantes tiveram a autonomia na escolha das demandas que se interessavam em atender.

Para alguns proponentes da ABP, a escolha feita pelo aluno pode ser o componente mais importante de um projeto da ABP (GRANT, 2002; LARMER; MERGENDOLLER, 2010 apud BENDER, 2014) e é crucial para se obter a participação ativa e apropriação do projeto por parte deles. Dessa forma, quando os estudantes escolhem realizar uma experiência de aprendizagem dessa natureza, é muito mais provável que participem ativamente de todas as fases do processo de 
aprendizagem se tiverem o poder de escolha sobre quais questões serão abordadas e quais atividades serão apostadas (BENDER, 2014, p. 45).

Dessa forma, como protagonistas desse processo, os estudantes realizaram uma escuta, investigaram a partir dela, elaboraram hipóteses e apresentaram uma proposta para atender à demanda, indicando quais caminhos iriam seguir - planejamento.

\subsubsection{Etapa de desenvolvimento}

Após a análise e exploração das demandas, e consequente organização do planejamento das ações, cada grupo definiu os processos para desenvolver seus respectivos projetos, interagindo com a realidade de cada demanda específica que escolheram atender, entendendo o problema, e como este deveria ser abordado e melhorado a fim de resolver os desafios propostos pelos demandantes. Nessa etapa, a definição dos papéis dentro do contexto do projeto foi fundamental para viabilizar as ações, conforme afirma Bender (2014).

Pela lógica do trabalho com projetos, a pesquisa de novos referenciais, tais como textos e demais recursos, deve ser estimulada. Sendo assim, além dos referenciais disponibilizados no PI3 - figura 7 -, os próprios estudantes se envolveram em novas buscas de referenciais e recursos, com o propósito de alcançar os objetivos estabelecidos em seus projetos. Isso acontece, porque o desenvolvimento dos projetos, considerando a abordagem $A B P$, normalmente envolve diferentes propostas, recursos, métodos e tecnologias.

Figura 7: Tela das pastas organizadas no Google Drive

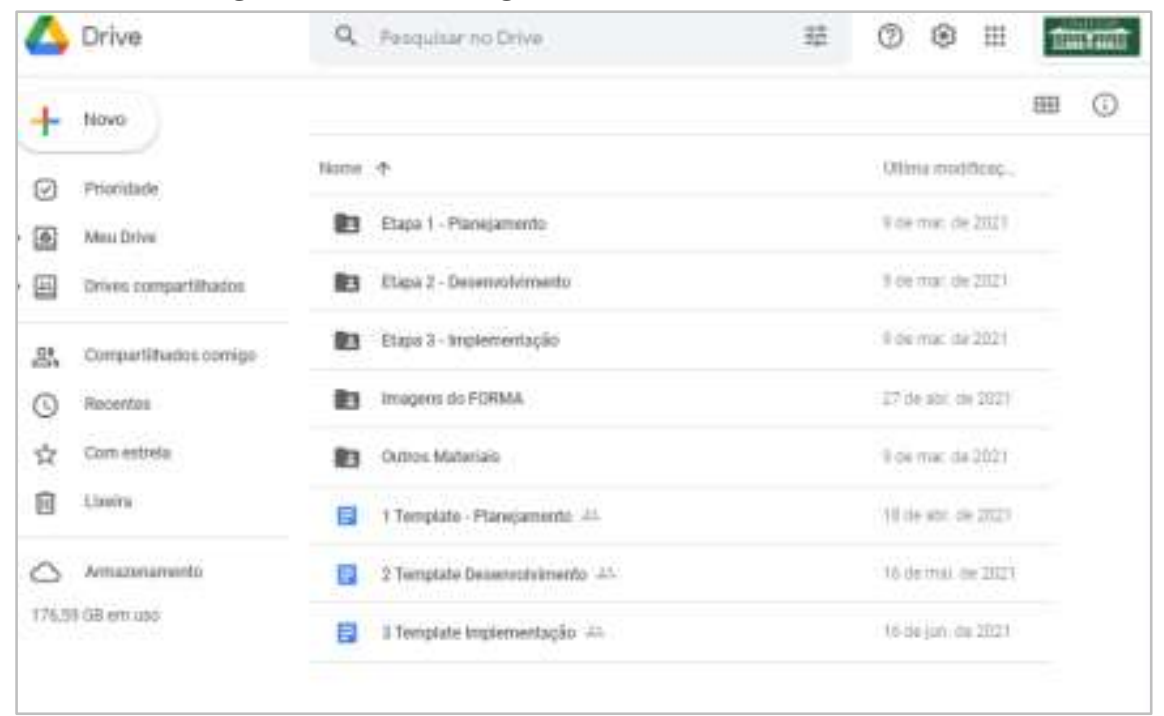

Fonte: captura de tela da pasta criada no drive e adicionada no AVA (2021).

\subsubsection{Etapa de implementação}

Por último, cada grupo implementou o que foi projetado, visando executar o plano inicial. Nessa etapa, em alguns projetos, foram disponibilizadas salas em ambientes virtuais de aprendizagem do Moodle, que é o ambiente definido institucionalmente. A disponibilização 
desses espaços e suas ferramentas tiveram como finalidade apoiar a implementação das propostas, oferecendo suporte tecnológico e pedagógico.

A abordagem da ABP encoraja os estudantes a participar do planejamento de projetos, desenvolver investigações e aplicação de conhecimentos novos para chegar a uma solução para o problema detectado ou a construção de produto (RULE; BARRERA, 2008 apud BENDER 2014).

As entregas de cada etapa foram alinhadas com o cronograma de cada bloco de disciplina da Unidade Curricular conforme é apresentado na figura a seguir.

Figura 8: Cronograma das disciplinas e indicação das etapas

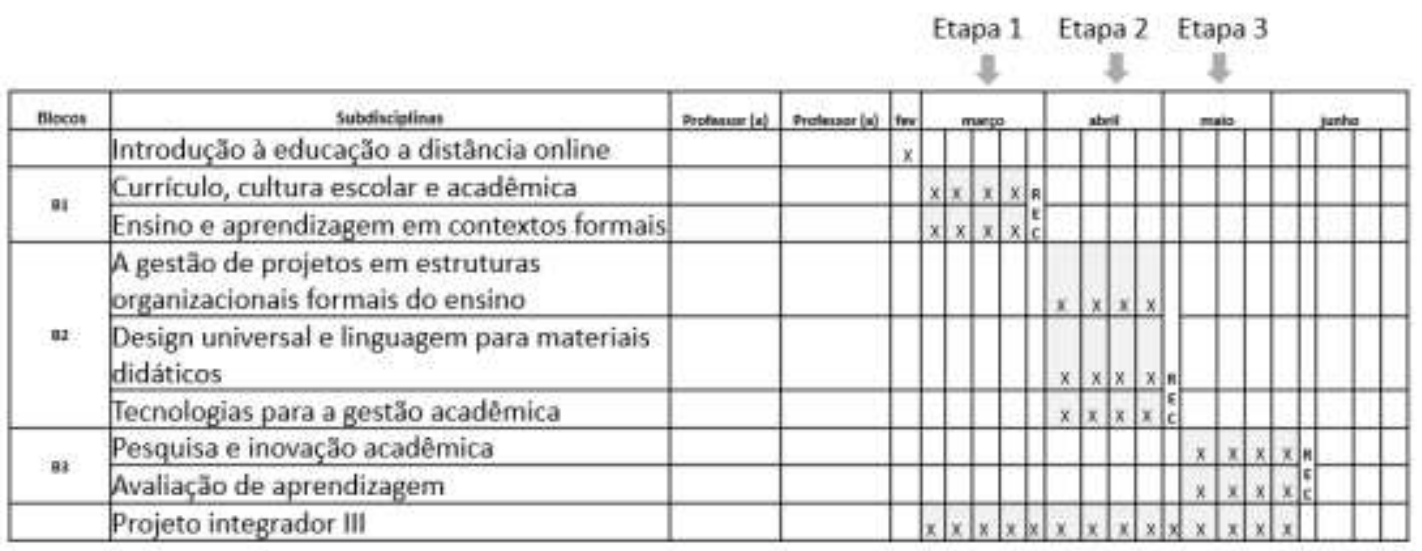

Fonte: elaborado pelos autores (2021).

\subsubsection{Organização dos processos avaliativos}

Mesmo estabelecendo um instrumento orientador para o desenvolvimento de cada etapa, cada grupo alcançou resultados distintos, adicionando conhecimentos diferentes. Além disso, diante de um mesmo projeto, evidenciou-se que os estudantes participantes atuaram de forma complementar, unindo suas competências e habilidades.

Dessa forma, o processo avaliativo foi desenvolvido de forma contínua a partir do acompanhamento dos grupos das entregas parciais e finais dos relatórios propostos - figuras 9 a 11 -; avaliação formativa por meio de feedbacks e orientações; e somativa com previsão de atribuição de pontuação ao longo das entregas e apresentações das etapas.

Vale esclarecer que essa avaliação não teve o intuito de comparar os projetos, mas sim analisar a evolução de cada grupo a partir das demandas apresentadas e entender como ocorriam a condução e execução desses projetos.

Para o cômputo das notas, foi proposto aos estudantes que realizassem uma autoavaliação. Nessa avaliação, os estudantes puderam refletir e atribuir uma nota ao seu trabalho. Para isso, utilizamos como referências, os seguintes critérios: (a) articulação com as disciplinas; (b) motivação pessoal para o desenvolvimento do projeto; (c) colaboração com os colegas nas tarefas do projeto; (d) pesquisa de soluções e propostas; (e) partilha de informações; (f) responsabilização para com o projeto; (g) autonomia; (h) cumprimento dos prazos; (i) participação e empenho na elaboração dos relatórios parciais; (j) participação e empenho na 
elaboração do relatório; e (l) apresentação final. Os relatórios parciais e finais foram postados no ambiente Moodle (Figuras 9, 10 e 11).

Figura 9: Ferramenta para a entrega da primeira etapa: planejamento

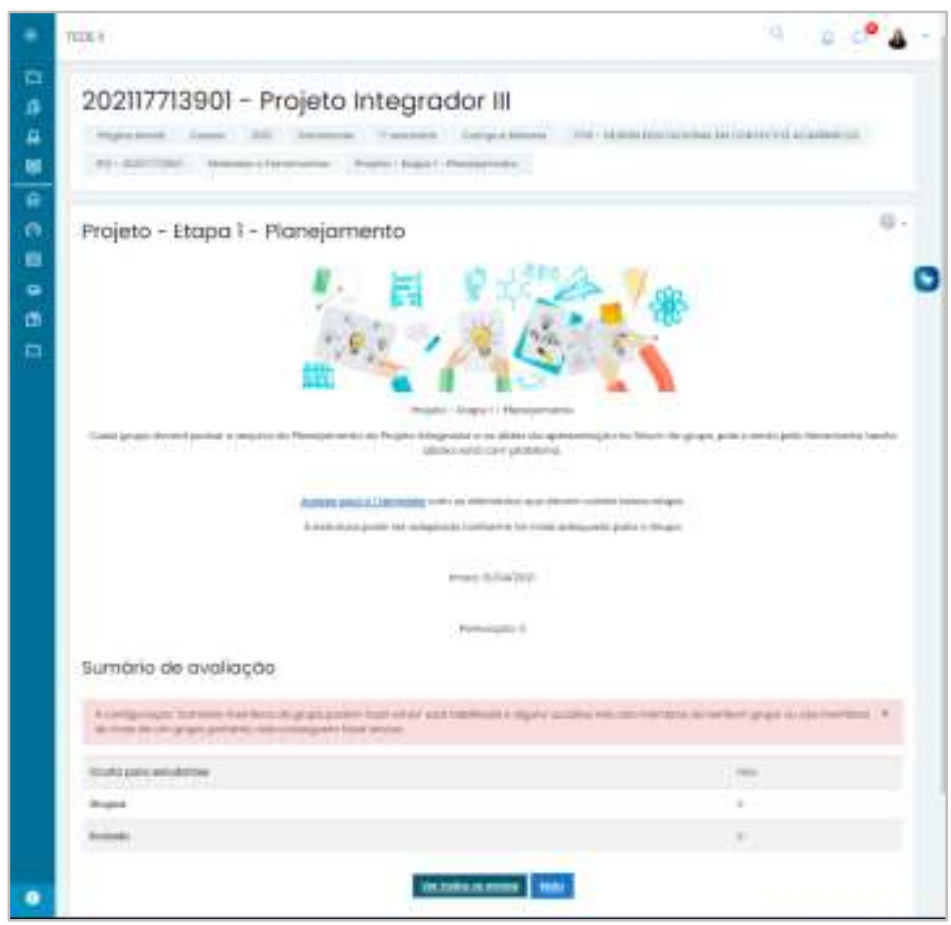

Fonte: captura de tela do AVA (2021).

Figura 10: Ferramenta para a entrega da segunda etapa: desenvolvimento

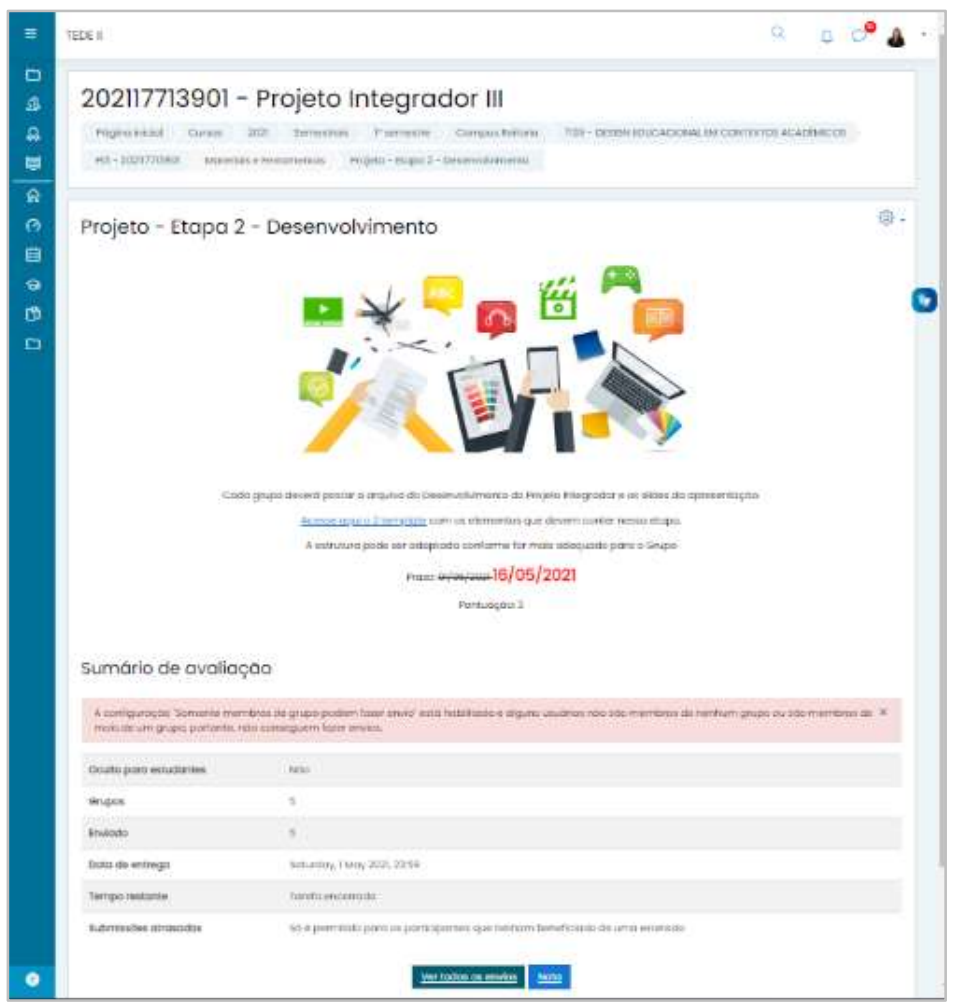

Fonte: captura de tela do AVA (2021). 
Figura 11: Ferramenta para a entrega da terceira etapa: implementação

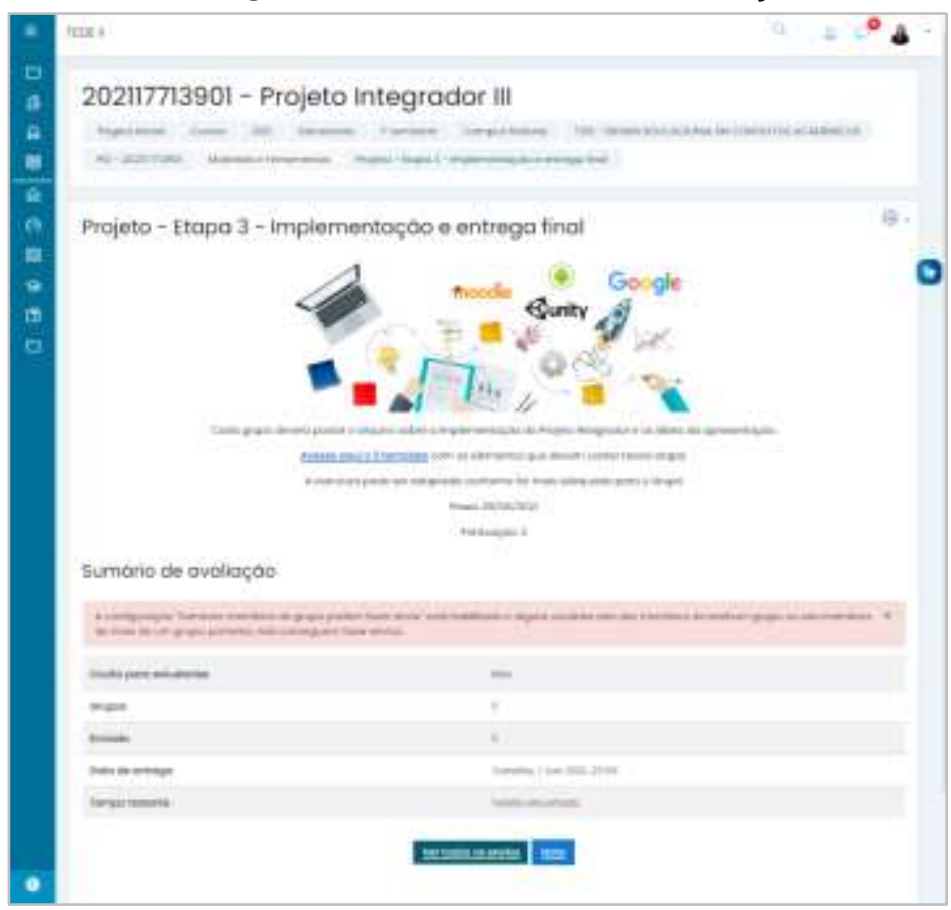

Fonte: captura de tela do AVA (2021).

Em relação à clareza e objetividade dos itens propostos nos templates das etapas: 1planejamento; 2-desenvolvimento; e 3-implementação, considerando uma escala de 1 a 5, sendo 1 pouco claros e objetivos e 5 muito claros e objetivos, evidencia-se que a maioria dos estudantes considerou que os itens foram claros e objetivos, pois as escalas com maior pontuação foram as 4 e 5, conforme demonstrado no Gráfico 5.

\section{Gráfico 5: Avaliação dos Templates}

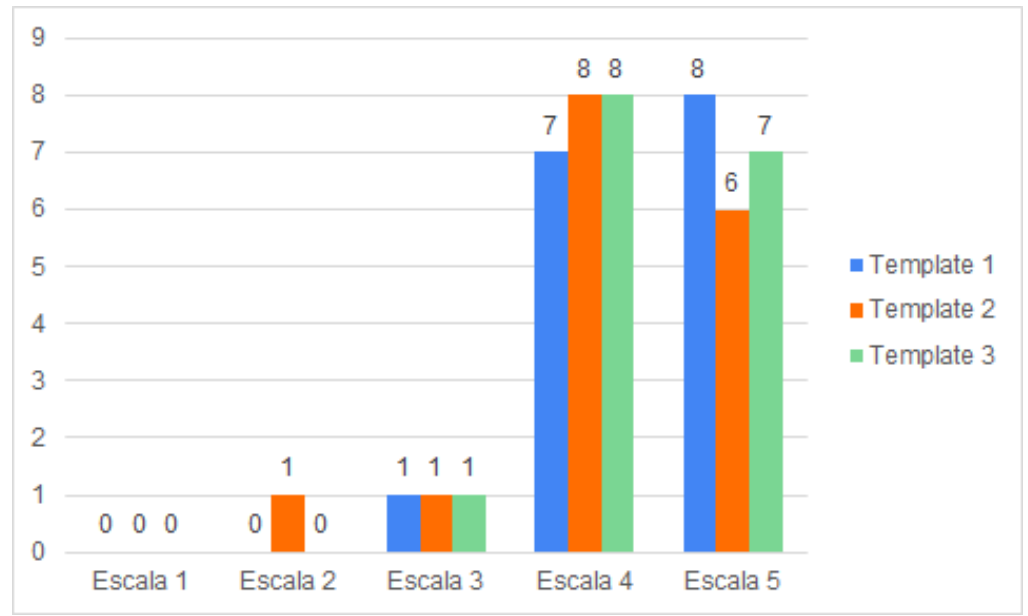

Fonte: elaborado pelos autores (2021). 


\subsubsection{Apresentação dos projetos}

Por meio das apresentações de cada etapa e das entregas dos relatórios, os estudantes foram explicando os elementos envolvidos na evolução dos protótipos. Nesse processo, eles esclareceram os conhecimentos que estavam adquirindo ao longo do percurso de elaboração dos projetos.

Considera-se que a entrega de relatórios parciais e a apresentação das etapas do projeto e dos artefatos construídos são fundamentais, uma vez que estimulam a comunicação, incentivam o grupo a evoluir em suas propostas e a se preparar, tendo em vista que a organização de relatórios, apresentação e defesa de suas ideias e projetos são bastante comuns no contexto profissional do designer educacional.

Antes da apresentação dos projetos, os professores-coordenadores se reuniram com os grupos. Em alguns momentos, foi preciso contar com a presença dos professores- colaboradores, pois foi necessário realizar uma validação interna. Essa reunião ocorreu em momentos diferentes para cada grupo, devido às demandas serem distintas e porque cada grupo apresentava um cronograma de condução e execução do projeto de forma distinta. Alguns projetos foram amplamente desenvolvidos, e outros se constituíram em protótipos para aprimoramentos futuros. A seguir são destacados alguns excertos a partir da autoavaliação reflexiva apresentada pelos estudantes.

Em relação à experiência de elaboração do protótipo junto à disciplina $\mathrm{PI} 3$, o processo foi intenso, com muitas dúvidas e dificuldades para a criação de soluções viáveis. Mas, toda a turbulência e dificuldades vivenciadas demonstrou para os alunos alguns aspectos centrais do trabalho do DE. [estudante P]

Participei de todas as etapas (...) sempre tentando encontrar as melhores soluções, principalmente nas questões macro, que foram as que eu menos tenho experiência em minha vida profissional e que me empenhei mais em desenvolver. [estudante M]

A solução desenvolvida ainda carece de muitas melhorias, sobretudo na customização do AVA, mas a proposta em si foi bem desafiadora e, acredito, atende ao escopo do que nos foi solicitado no âmbito do PI3. [estudante C]

$\mathrm{Na}$ apresentação das etapas 1, 2 e 3 dos projetos e na apresentação final, os professores das disciplinas foram convidados a participar com a finalidade de tecer considerações sobre os projetos desenvolvidos, sobre o formato das apresentações, bem como com o objetivo de avaliar os projetos. Nessas apresentações, a participação de todos os estudantes também foi requerida, uma vez que se considera importante a partilha das propostas e das soluções encontradas por cada grupo. 
De modo simultâneo às etapas previstas - planejamento, desenvolvimento e implementação - os professores-coordenadores dos projetos desenvolveram ações no sentido de contribuir e enriquecer os processos de ensino e aprendizagem dos estudantes. Nesse sentido, foram propostos encontros síncronos com os professores do TEDE - intitulados de LabPI -, tendo em vista as demandas apresentadas pelos grupos e que eram articuladas ao conteúdo das disciplinas ministradas na Unidade Curricular.

Foram desenvolvidos encontros síncronos com professores, pesquisadores e professores externos. A atividade que contou com a participação de convidados externos foi intitulada de Webinar, em que foram apresentadas contribuições significativas para os processos que estavam sendo vivenciados pelos estudantes.

As temáticas de cada Webinar versaram sobre: planejamento e gestão de projetos do Design Educacional; direitos autorais e digitais na educação a distância e; recursos tecnológicos empregados em projetos de Design Educacional. Neste último, foram considerados conteúdos como: jogos à gamificação, ferramenta h5p e ferramentas do Google for Education.

\section{CONSIDERAÇÕES FINAIS E MELHORIAS INDICADAS PELOS ALUNOS}

A avaliação aplicada aos estudantes para que analisassem a disciplina contou com respostas abertas por meio das quais os estudantes puderam sugerir melhorias para futuras ofertas dessa disciplina.

Em relação ao ambiente, foi sugerido que os espaços: Cronograma Geral, LabPI Apresentação e Webinar aberto poderiam se tornar um único item para centralizar as informações de datas importantes, eventos e links.

Sobre o uso do WhatsApp, foi considerado como uma ótima ferramenta para recados rápidos; no entanto, foi alertado por meio de comentários dos estudantes sobre o cuidado na postagem de referências bibliográficas, pois elas podem ser perdidas ao longo da conversa. Também foi sugerido a ferramenta Telegram, uma vez que, por meio dessa ferramenta, a gestão das informações e dos anexos é gerenciada de forma melhor.

Outro aspecto indicado foi que a gestão e o andamento dos trabalhos realizados pelos grupos fossem acompanhados pelos professores-coordenadores do projeto por meio de software específico. Essa sugestão foi acompanhada da seguinte reflexão pelos alunos "na minha opinião a gestão é o maior desafio de projetos desse tipo e um fator que pode prejudicar a participação dos integrantes de forma isonômica". Também foi sugerido que no processo avaliativo fosse considerada a avaliação entre pares e que os encontros síncronos onde ocorriam as apresentações dos projetos fossem durante a semana.

Durante as recomendações apresentadas pelos estudantes para o aprimoramento das próximas ofertas da disciplina Projeto Integrador 3, houve apontamentos positivos sobre a experiência vivenciada, destacadas a seguir no encerramento deste texto: 
A proposta do PI ao apresentar uma demanda real foi espetacular. É claro, que a equipe contribuiu muito para o bom desenvolvimento do projeto, mas obter um resultado concreto do projeto a partir da implementação do produto foi muito significativo para mim. [estudante A]

Achei o PI desse semestre extremamente organizado. Parabéns pelo trabalho! [estudante $\mathrm{H}$ ]

A organização do PI me surpreendeu positivamente. A complexidade da proposta me fez duvidar um pouco no início, mas logo percebi que tudo era muito bem planejado, desenvolvido e implementado. [estudante $\mathrm{M}$ ]

Foi muito enriquecedor aprender fazendo. Muito obrigada a todos os professores que participaram do nosso aprendizado enquanto estudantes do TEDE. Gostei muito da trilha formativa deste PI3. Muito bom. [estudante J]

O fato de os orientadores e demandantes se fazerem presentes e estarem tão acessíveis, apesar da distância física, contribuiu para a riqueza do projeto desenvolvido. [estudante A]

Este foi sem dúvida o $\mathrm{PI}$ em que me senti mais estimulado a participar, a relevância e a aplicação real do tema foram muito importantes e serviram como uma ótima experiência. [estudante F]

A partir dos relatos finais conclui-se que a experiência foi positiva e significativa, tanto para os alunos como para os professores do curso, entendendo que a disciplina de Projeto Integrador 3, ancorada na metodologia da ABP, possibilitou o desenvolvimento de competências específicas, práticas e aplicadas do Designer Educacional no contexto da educação formal. Os resumos dos projetos gerados na disciplina Projeto Integrador 3 foram apresentados no VIII Congresso acadêmico da Unifesp: universidade e defesa da vida, trazendo maior significação da experiência para os alunos, demandantes e professores-coordenadores dos projetos.

\section{REFERÊNCIAS}

BENDER, W. N. Aprendizagem baseada em Projetos: Educação Diferenciada para o Século XXI. São Paulo: Penso, 2014.

COSTA, Y.Y. K. Aprendizagem Baseada em Projetos. Curitiba: Contentus, 2020.

FAZENDA, I. (org.). Dicionário em construção: interdisciplinaridade. 2.ed. São Paulo: Cortez, 2002.

UNIVERSIDADE ABERTA DO BRASIL (UAB-UNIFESP). Projeto Pedagógico de Curso Superior de

Tecnologia em Design Educacional. São Paulo: Núcleo UAB/UNIFESP, 2016.

YARED, Y. O que é interdisciplinaridade. In: FAZENDA, I. (org.). 0 Que é interdisciplinaridade? São Paulo: Cortez, 2008. 